Arq. Bras. Med. Vet. Zootec., v.68, n.4, p.1033-1042, 2016

\title{
Indicadores de desempenho de fazendas leiteiras de Minas Gerais
}

\author{
[Performance indicators of Minas Gerais dairy farms] \\ M.N. Pereira ${ }^{1}$, J.C. Resende ${ }^{2}$, R.A.N. Pereira ${ }^{3}$, H.C.M. Silva ${ }^{4}$ \\ ${ }^{1}$ Universidade Federal de Lavras- Lavras, MG \\ ${ }^{2}$ Embrapa Gado de Leite- Juiz de Fora, MG \\ ${ }^{3}$ Empresa de Pesquisa Agropecuária de Minas Gerais- URESM-Lavras, MG \\ ${ }^{4}$ Universidade Federal de Minas Gerais, EV-UFMG - Belo Horizonte, MG
}

\section{RESUMO}

Foram avaliados indicadores de desempenho de 159 fazendas de leite da região Triângulo Mineiro-Alto Paranaíba no estado de Minas Gerais, em 2007 e 2008. Os dados foram obtidos mensalmente por 18 consultores privados. A produção de leite foi de $770 \pm 697 \mathrm{~L} / \mathrm{d}$, oriunda de $81 \pm 54$ vacas em lactação, exploradas em $109 \pm 75$ ha. A produção anual de leite por hectare foi de $3333 \pm 2.720 \mathrm{~L}$, oriunda de $0,70 \pm 0,44$ vacas em lactação/ha, por vaca adulta foi de $3383 \pm 1.269 \mathrm{~L}$, e $26 \pm 8 \%$ do rebanho adulto era não lactante. A produção de leite por mão-de-obra contratada foi $103342 \pm 44616 \mathrm{~L}$. Concentrados constituíram $30 \%$ e mão-de-obra $10 \%$ do custo de produção. A renda líquida foi em média positiva, mas o resíduo foi negativo em 15 e $25 \%$ das fazendas, quando a estimativa de custo computou ou não os juros sobre o valor dos bens, respectivamente. Os indicadores de lucratividade foram: renda líquida anual $\mathrm{R} \$ 32841,00$; renda líquida anual sobre o valor dos bens $4,7 \%$; e renda líquida sobre a renda bruta $8,7 \%$. Mesmo com desempenho acima das médias brasileira e mineira, os indicadores de desempenho foram modestos, sugerindo existir oportunidade para ganho em eficiências produtiva e financeira.

Palavras-chave: pecuária leiteira, custo de produção, produtividade, rentabilidade, Brasil

\begin{abstract}
Performance indicators of 159 dairy farms in the Triângulo Mineiro-Alto Paranaíba region of the Minas Gerais state, in 2007 and 2008, were evaluated. Data was obtained monthly by 18 private consultants. Milk yield was $770 \pm 697 \mathrm{~L} / \mathrm{d}$, from $81 \pm 54$ lactating cows, and $109 \pm 75$ ha were explored. Yearly milk yield per hectare was $3,333 \pm 2,720 \mathrm{~L}$, from $0.70 \pm 0.44$ lactating cows/ha, per adult cow was $3,383 \pm 1,269 \mathrm{~L}$, and $26 \pm 8 \%$ of the adult herd was non-lactating. Milk yield per hired labor was 103,342 $\pm 44,616 \mathrm{~L}$. Concentrates cost was $30 \%$ and labor $10 \%$ of the production cost. The mean net income was positive, but 15 and $25 \%$ of the farms had negative residue, when cost was estimated computing or not the interest on assets value, respectively. Profitability indicators were: annual net income $R \$ 32,841.00$; annual net income over assets value 4.7\%; and net income over gross income $8.7 \%$. Even though performance was above Brazilian and Minas Gerais means, performance indicators were modest, suggesting that there is opportunity for gain in productive and financial efficiencies.
\end{abstract}

Keywords: dairy farming, production cost, productivity, profitability, Brazil

\section{INTRODUÇÃO}

Apesar de o Brasil ser o quarto maior produtor de leite bovino do mundo, a produtividade anual ao redor de $1680 \mathrm{~L} /$ vaca é baixa quando comparada à dos Estados Unidos, de 9850 L/vaca, da China de 4040 L/vaca, da Rússia de 3740 L/vaca, da Argentina de 5830 L/vaca, da

Recebido em 25 de fevereiro de 2015

Aceito em 30 de maio de 2016

E-mail: mpereira@dzo.ufla.br
União Européia de 6140 L/vaca e da Nova Zelândia de 4060 L/vaca (United..., 2012). Entretanto, a metodologia censitária do IBGE, por incluir fazendas de gado de corte que comercializam algum excedente de leite dos bezerros, pode não traduzir a realidade das fazendas leiteiras. Em Minas Gerais, Reis et al. (2001) observaram produção por vaca por ano de 3548 L; Oliveira et al. (2001) de 3728 L, e 
Fassio et al. (2006) de 4157 L. Em 2011, Minas Gerais produziu $27,3 \%$ do leite brasileiro (Instituto..., 2011), sendo o Triângulo MineiroAlto Paranaíba a principal mesorregião produtora do estado. Compreender indicadores zootécnicos de rebanhos localizados nesta mesorregião pode impactar o leite mineiro e nacional, sugerindo pontos de atuação para melhorar a eficiência econômica da atividade.

O Projeto Educampo, criado e coordenado pelo Sebrae/MG (Serviço..., 2008), tem por estratégia introduzir processos de produção e gestão, prestando serviço privado de consultoria aos produtores, e assistência a mais de mil fazendas de leite mineiras. Além do apoio com assistência especializada, os consultores do programa armazenam dados das fazendas utilizando metodologia padronizada, permitindo a geração de indicadores econômicos comparáveis.

Este trabalho foi realizado com o objetivo de descrever indicadores de desempenho zootécnico e econômico de fazendas leiteiras acompanhadas pelo Projeto Educampo na mesorregião Triângulo Mineiro-Alto Paranaíba de Minas Gerais, entre agosto de 2007 a julho de 2008.

\section{MATERIAL E MÉTODOS}

Dezoito consultores do projeto Educampo (Serviço..., 2008) com formação em agronomia, veterinária ou zootecnia foram responsáveis pelo registro dos dados, feito por meio de planilha eletrônica por ocasião das visitas mensais às fazendas. $\mathrm{O}$ arquivo final foi composto por dados de 159 fazendas localizadas em 29 municípios da mesorregião Triângulo Mineiro-Alto Paranaíba de Minas Gerais: Abadia dos Dourados, Água Comprida, Araxá, Campo Florido, Carmo do Paranaíba, Conceição das Alagoas, Conquista, Coromandel, Cruzeiro da Fortaleza, Delta, Guimarânia, Gurinhatã, Ibiá, Ipiaçu, Ituiutaba, Monte Alegre de Minas, Patrocínio, Perdizes, Prata, Sacramento, Santa Vitória, Tapira, Tiros, Uberaba, Uberlândia, Varjão de Minas, Vazante e Veríssimo. Onze fazendas foram descartadas do arquivo inicial por conter informações incompletas. Cinco fazendas da amostra final não dispunham de terra própria e produziam leite em áreas arrendadas.

O gasto de cada mês foi corrigido mensalmente para julho de 2008, pelo Índice Geral de Preços Disponibilidade Interna (IGP-DI) da Fundação
Getúlio Vargas (Fundação..., 2009). Os valores mensais corrigidos foram somados, gerando o custo total para o período. Os valores da terra, do rebanho e de outros bens de produção foram estimados para julho de 2008. A área de terra considerada foi a utilizada com pastagens, com produção de alimentos (forragens e grãos) e com benfeitorias.

A produção de leite foi a quantidade total ordenhada, incluindo o leite efetivamente vendido e o consumido na fazenda pela família, bezerros e mão-de-obra. A renda bruta do leite (RB leite) foi calculada considerando o preço do leite vendido. A renda bruta total (RB total) considerou a RB leite, venda de animais e de produtos excedentes, e a variação do inventário animal, valor utilizado para corrigir eventuais distorções no valor do rebanho oriundas de vendas ou compras excessivas de animais (Nascif, 2008).

O capital investido (BENS) foi estimado considerando o estado de conservação e os preços de cada item no mercado regional. Foram considerados: rebanho, benfeitorias, máquinas, tratores, veículos, equipamentos, utensílios, ferramentas e outros bens fixos de produção. $\mathrm{O}$ capital em terra foi estimado pelo preço da terra nua ocupada com a exploração.

O custo total 1 (CT1) considerou o gasto com compra ou produção de alimentos concentrados, com mão-de-obra contratada e com outras despesas diretas e depreciação do capital investido. $\mathrm{O}$ critério de depreciação foi $\mathrm{o}$ escolhido pelo consultor no momento de fazer a avaliação, levando em conta o valor atual, o valor residual e a vida útil remanescente de cada bem depreciado. $\mathrm{O}$ custo total médio (CTM1) foi calculado pela divisão do CT1 pelo volume de leite produzido. No custo total 2 (CT2) e custo total médio 2 (CTM2) foram acrescentados os juros sobre o capital investido, exceto em terra, considerando a taxa de $6 \%$ ao ano. Não foi considerada a remuneração da mão-de-obra familiar. Os valores foram corrigidos pelo IGPDI para julho de 2008.

Três indicadores de lucratividade foram calculados: renda líquida anual (RL), taxa de retorno sobre o capital investido em bens (TRB) e margem de lucro (ML). A RL foi obtida pela diferença entre a RB total e o CT1 ou CT2, resultando em valores de RL1 ou RL2, 
respectivamente. Os valores de RL1 e RL2 foram então expressos como proporção dos BENS para gerar a TRB, e como proporção da RB total, para a ML. Os valores de RL também foram expressos por unidade produtiva (vacas), por unidade de mão-de-obra contratada e por hectare utilizado na atividade.

Estatísticas descritivas (média, desvio-padrão, coeficiente de variação, valor mínimo e valor máximo) foram utilizadas para descrever o banco de dados. O relacionamento entre algumas variáveis foi avaliado.

\section{RESULTADOS E DISCUSSÃO}

Além de fatores ligados à eficiência zootécnica, próprios de cada fazenda, o ambiente macroeconômico determina a lucratividade da atividade leiteira. Os anos de 2007 e 2008 foram de preços elevados para os produtos lácteos, refletindo a tendência de alta nos preços ao produtor iniciada em 2002 (International..., 2009). Produtores brasileiros chegaram a receber US\$ 0,48 por $\mathrm{kg}$, em junho de 2008 , um preço histórico até então nunca obtido (Centro..., 2009). Entre agosto de 2007 e julho de 2008, o preço médio recebido pelos produtores brasileiros, $\mathrm{R} \$$ 0,78/litro, foi $24 \%$ maior do que a média desses mesmos meses nos últimos dez anos. Os indicadores aqui gerados referem-se a um período de bom pagamento do leite ao produtor.

Os produtores de leite desta amostra não foram obtidos ao acaso dentre os atuantes na região estudada e diferem do produtor médio quanto à disposição de pagarem pelo serviço de consultoria técnica, fato não prevalente entre os produtores de leite do Brasil. Outra diferença é a prática sistemática de registros zootécnicos e econômicos, condição para participarem do programa Educampo (Serviço..., 2008). É sabido que apenas $18 \%$ dos produtores de leite de Minas Gerais mantêm algum tipo de escrituração em seus rebanhos (Federação..., 2006). Entretanto, a idade média, ao redor de 51 anos (Tab. 1), a grande maioria entre 40 e 60 anos (Tab. 2), assemelha-se aos 50 anos dos produtores do Triângulo-Alto Paranaíba (Federação..., 2006) e aos 51 dos de Goiás (Federação..., 2009). A idade média dos produtores de Minas Gerais foi de 52,1 anos no levantamento da FAEMG (Federação..., 2006). A similaridade nas idades sugere que a motivação para adoção de um programa contínuo e privado de assistência técnica pelos participantes deste estudo não decorreu do suposto empreendedorismo dos mais jovens.

Tabela 1. Variáveis descritivas da amostra de 159 fazendas produtoras de leite da mesorregião Triângulo Mineiro-Alto Paranaíba, MG

\begin{tabular}{lccccc} 
& Média & DP & CV & Min & Max \\
\hline Leite produzido (L/d) & 769,6 & 696,6 & 901 & 100,7 & 5644,9 \\
Área ocupada com leite (ha) & 108,7 & 75,1 & 69 & 8 & 380 \\
Vacas em lactação & 58,7 & 38,9 & 66 & 11,3 & 276,0 \\
Vacas adultas & 80,9 & 54,5 & 67 & 14,7 & 386,1 \\
Gado jovem & 87,5 & 62,5 & 71 & 14,0 & 377,7 \\
Rebanho total & 168,5 & 112,9 & 67 & 32,6 & 763,8 \\
Mão-de-obra contratada & 2,6 & 2,0 & 76 & 1,0 & 20,1 \\
Valor da terra (x R $\$ 1.000,00 / h a)$ & 5,09 & 2,56 & 5 & 1,04 & 21,32 \\
Distância da cidade (km) & 27,4 & 17,0 & 62 & 1,0 & 98,0 \\
Idade do proprietário (anos) & 50,6 & 10,9 & 22 & 27,0 & 78,0 \\
Escolaridade do proprietário (anos) & 12,9 & 3,9 & 30 & 4 & 17 \\
\hline DP=desvio-padrão. CV=coeficiente de variação. Min=valor mínimo. Max=valor máximo. ${ }^{1}$ Relativo a 154 fazendas.
\end{tabular}

A escolaridade dos proprietários, 12,9 anos em escola formal (Tab. 1), foi mais alta que a da média mineira, de apenas 5,2 anos (Federação..., 2006), e a de Goiás, 6 anos (Federação..., 2009). Baixa escolaridade de proprietários de fazendas leiteiras tem sido relatada em outras partes do mundo, como na Polônia, onde apenas 16,2\% dos fazendeiros possuía o ensino secundário completo, considerado como um possível limitante da eficiência na pecuária daquele país (Latruffe et al., 2004). A escolaridade dos produtores desta amostra, maior que a média regional, pode ter contribuído para a adoção da consultoria do Educampo, sugerindo que educação formal pode determinar a eficiência em fazendas mineiras. 
Tabela 2. Proporção em classes de algumas variáveis em 159 fazendas produtoras de leite da mesorregião Triângulo Mineiro-Alto Paranaíba, MG

\begin{tabular}{cccc}
\hline Variável & $\%$ & Variável & $\%$ \\
\hline Leite produzido (L/d) & & Área (ha) & 28,9 \\
$250-500$ & 11,9 & $<50$ & 25,8 \\
$500-1000$ & 34,0 & $50-100$ & 18,2 \\
$1000-1500$ & 30,2 & $100-150$ & 13,8 \\
$1500-3500$ & 13,8 & $150-200$ & 10,1 \\
$>3500$ & 9,4 & $200-250$ & 3,1 \\
\hline Vacas em lactação & 0,6 & $>250$ & 35,2 \\
$25-50$ & & & 47,2 \\
$50-75$ & 10,7 & Vacas em lactação/Área (/ha) & 11,3 \\
$75-100$ & 40,9 & $0,5-1,0$ & 6,3 \\
$100-200$ & 26,4 & $1,0-1,5$ & \\
$>200$ & 10,7 & $>1,5$ & 2,5 \\
\hline$<25$ & 10,7 & & 17,6 \\
Leite/Vaca em lactação (L/ano) & 0,6 & & 31,4 \\
$3000-4000$ & 14,4 & Idade do proprietário (anos) & 27,0 \\
$4000-5000$ & 20,1 & $30-40$ & 17,0 \\
$5000-6000$ & 30,8 & $40-50$ & 4,4 \\
\hline $6000-7000$ & 20,8 & $50-60$ & $60-70$ \\
$>7000$ & 9,4 & $>70$ & \\
\hline
\end{tabular}

As fazendas utilizavam, em média, 2,6 empregados contratados (Tab. 1), número mais alto que o encontrado nas fazendas leiteiras de Minas Gerais e Goiás, com 0,4 (Federação..., 2006) e 1,3 funcionários (Federação..., 2009), respectivamente. Este fato é coerente ao maior tamanho dos rebanhos estudados (Tab. 1 e 2). O rebanho em lactação da amostra foi praticamente o dobro do relatado para o estado de Goiás, de 26,5 vacas (Federação..., 2009). A quantidade de vacas adultas no rebanho da amostra foi, aproximadamente, 4,8 vezes maior que a média nacional, de 17 vacas (Instituto..., 2009). Entretanto, comparativamente à média de outros países, os números desta amostra de produtores, teoricamente progressistas para a região estudada, são modestos. A fazenda média dos EUA tem 135 vacas, a da Argentina 156 e a da Nova Zelândia cerca de 351 vacas adultas (Food..., 2009; International..., 2009). Na amostragem de Bolton e Vanderlin (2009), por exemplo, envolvendo custos de 544 fazendas do Wisconsin, EUA, o rebanho médio continha 147 vacas adultas. $\mathrm{O}$ baixo número de vacas, associado à menor produção por vaca (Tab. 3) que a obtida em outras regiões no mundo tradicionalmente leiteiras, reflete uma realidade da indústria brasileira: alto número de fazendas em proporção ao volume total de produção.

A produção diária de 770 litros (Tab. 1) foi acima da média nacional de 52 litros (Instituto..., 2009), da mineira de 184 litros (Federação..., 2006) e da goiana de 245 litros (Federação..., 2009). O valor observado foi semelhante ao da Alemanha, ao redor de 800 litros, mas menor que os 2208 litros da Argentina, 3225 litros dos Estados Unidos e 4100 litros da Nova Zelândia (International..., 2009). Apenas 10\% das fazendas da amostra produziram mais de 1500 litros por dia, enquanto $45 \%$ tinham mais de 100 hectares (Tab. 2). A produção por hectare foi pouco acima de 3000 litros por ano (Tab. 3), denotando uso pouco intensivo do fator terra, já que produções acima de 15000 litros são metas plausíveis no Brasil (Silva et al., 2006; Vilela et al., 2006; Stock, 2007). Estes dados sugerem que a disponibilidade de terra não foi $o$ maior determinante do volume de produção, coerente com o valor de 0,45 para o coeficiente de correlação linear entre a área e o volume de produção. 
Indicadores de desempenho...

Tabela 3. Indicadores zootécnicos da amostra de 159 fazendas produtoras de leite da mesorregião Triângulo Mineiro-Alto Paranaíba, MG

\begin{tabular}{|c|c|c|c|c|c|}
\hline & Média & DP & $\mathrm{CV}$ & Min & Max \\
\hline Vacas secas/Vacas adultas (\%) & 26,5 & 8,2 & 31 & 10,8 & 52,6 \\
\hline Vacas em lactação/Vacas secas & 3,16 & 1,36 & 43 & 0,90 & 8,30 \\
\hline Vacas em lactação/Rebanho total (\%) & 36,1 & 7,9 & 22 & 21,5 & 58,8 \\
\hline Gado jovem/Rebanho total (\%) & 51,0 & 8,4 & 16 & 25,1 & 72,2 \\
\hline Vacas em lactação/Área (ha) & 0,70 & 0,44 & 63 & 0,17 & 2,62 \\
\hline Vacas adultas/Ấrea (ha) & 0,95 & 0,58 & 61 & 0,24 & 3,34 \\
\hline Rebanho total/Área (ha) & 1,94 & 1,08 & 56 & 0,53 & 6,55 \\
\hline Leite/Vaca em lactação (L/ano) & 4528 & 1403 & 31 & 1500 & 9778 \\
\hline Leite/Vaca adulta (L/ano) & 3383 & 1269 & 38 & 1067 & 8124 \\
\hline Leite/Área (L/ano) & 3333 & 2720 & 82 & 493 & 15906 \\
\hline Leite/Mão-de-obra contratada (L/ano) & 103342 & 44616 & 43 & 18575 & 220748 \\
\hline
\end{tabular}

$\mathrm{DP}=$ desvio-padrão; $\mathrm{CV}=$ coeficiente de variação; Min=valor mínimo; Max=valor máximo.

Com base no coeficiente de variação, o indicador produção por vaca foi menos variável entre fazendas que o indicador produção por área (Tab. 3). Este fato parece denotar que fatores ligados ao manejo ou à genética animal foram mais estáveis entre fazendas que as práticas ligadas à produção de forragens. Variabilidade na fertilidade do solo, definida por diferenças geográficas ou nas práticas de cultivo adotadas, ou no tipo da forragem, pode explicar a maior variabilidade na produtividade da terra que na produtividade animal.

Neste cenário de produção leiteira, a correlação entre a RL1 por hectare e a produção de leite por hectare foi de 0,60 , sendo a produção de leite por hectare mais determinada pela taxa de lotação do que pela produtividade animal. A produção de leite por hectare, correlacionou-se a 0,85 com o número de vacas adultas e a 0,92 com o número de vacas em lactação por hectare, enquanto as correlações foram de 0,58 e 0,56 com a produção anual por vaca adulta ou por vaca em lactação, respectivamente.

A taxa de lotação, ao redor de 0,7 vacas em lactação por hectare (Tab. 3), foi praticamente o dobro da de Minas Gerais e de Goiás, em torno de 0,4 e 0,3, respectivamente (Federação..., 2006; Federação..., 2009). O valor observado foi similar ao relatado para produtores de leite tipo B em São Paulo, em torno de 0,4 a 1,0 (Schiffler et al., 1999), e mais baixo que o da região de Castro no Paraná, entre 1,2 e 2,1 (Silva et al., 2006). Vilela et al. (2006) relataram pastagens tropicais irrigadas com 7,3 vacas em lactação por hectare, considerando somente esta categoria animal na pastagem. Com todas as categorias seriam 4,0 vacas em lactação/ha, lotação que leva a mais de 20000 litros de leite/ha/ano, se obtidos, pelo menos, 14 litros diários por vaca. Em 11346 fazendas neozelandesas em pastagens de áreas temperadas, a taxa de lotação foi de 2,83 vacas por hectare (New..., 2008). O potencial de produção de forragens em zonas tropicais parece não ter sido adequadamente explorado nas fazendas deste estudo.

Uma prática de manejo adotada unanimemente pelas fazendas foi o uso de alimentos concentrados, coerente com a alta produção de grãos e disponibilidade de subprodutos agroindustriais na região em estudo (Minas..., 2010). Apesar de a produção anual por vaca adulta ter sido ao redor de 3400 litros (Tab. 3), praticamente o dobro da relatada pelo IBGE (Instituto..., 2009) para o Brasil, em torno de 1237 litros em 2006 e mais alta que a média mineira relatada pela Federação da Agricultura, em torno de 2950 litros (Federação..., 2006), esta foi mais baixa que a da Nova Zelândia (3567 litros), com dieta composta exclusivamente por pastagem temperada (New..., 2008).

Uma característica da pecuária leiteira brasileira é a prevalência de baixos índices de produtividade em dietas que utilizam alimentos concentrados, algo que pode penalizar a competitividade do país no mercado internacional de lácteos. O custo de alimentos concentrados por litro de leite produzido foi ao redor de $\mathrm{R} \$ 0,27$, representando cerca de $30 \%$ do custo total, três vezes mais alto que o custo da mão-de-obra (Tab. 4). Redução do custo de concentrados por litro de leite, obtida por diluição da exigência nutricional de mantença 
por maior produção por vaca, por melhoria na qualidade das forragens ou por menor custo por unidade de concentrado produzido ou comprado, pode ser uma rota efetiva para induzir ganho de eficiência nestas fazendas.

O custo da mão-de-obra contratada, ao redor de $\mathrm{R} \$ 0,10$ por litro de leite (Tab. 4), foi semelhante ao verificado nas menores fazendas de leite da Argentina, Nova Zelândia e Estados Unidos (International..., 2009). No entanto, foi quase duas vezes maior que nas maiores fazendas destes três países. O baixo custo em grandes fazendas da região sul do Brasil (Silva et al., 2006) comprova que é possível competir até com a Argentina, onde estão os menores custos de mão-de-obra entre os países grandes produtores (International..., 2009). Não se trata, portanto, de uma amostra de fazendas competitivas no mercado internacional, se considerado o custo da mão-de-obra contratada como único fator de competição. Baixos salários relativos no Brasil não são suficientes para reduzir o custo da mãode-obra se as fazendas utilizam pouco capital poupador de trabalho.

Tabela 4. Indicadores contábeis da amostra de 159 fazendas produtoras de leite da mesorregião Triângulo Mineiro-Alto Paranaíba, MG

\begin{tabular}{lccccc}
\hline & Média & DP & CV & Min & Max \\
\hline Custo de concentrados (R\$/L) & 0,2711 & 0,0711 & 26 & 0,0407 & 0,5020 \\
Custo de mão-de-obra contratada (R\$/L) & 0,0959 & 0,0583 & 61 & 0,0000 & 0,2948 \\
Custo mão-de-obra/Custo concentrados & 0,4071 & 0,4216 & 104 & 0,0 & 3,9642 \\
& & & & & \\
& 0,8272 & 0,2122 & 26 & 0,3717 & 2,0194 \\
Custo total médio 1 1 (R\$/L) & 33,8 & 9,1 & 27 & 5,5 & 54,1 \\
Custo de concentrados/custo total 1 (\%) & 11,2 & 5,8 & 52 & 0,0 & 26,2 \\
Custo de mão-de-obra/custo total 1 (\%) & & & & & \\
& 0,9182 & 0,2494 & 27 & 0,4298 & 2,5319 \\
Custo total médio 2 (R\$/L) & 30,7 & 8,7 & 28 & 4,0 & 48,2 \\
Custo de concentrados/custo total 2(\%) & 10,1 & 5,1 & 51 & 0,0 & 22,4 \\
Custo de mão-de-obra/custo total 2 (\%) & & &
\end{tabular}

$\mathrm{DP}=$ desvio-padrão; $\mathrm{CV}=$ coeficiente de variação; Min=valor mínimo; Max=valor máximo. ${ }^{1}$ Custo total médio $1=($ despesa com concentrados + despesa com mão-de-obra contratada + outras despesas diretas + depreciação)/leite produzido. ${ }^{2}$ Custo total médio $2=($ despesa com concentrados + despesa com mão-de-obra contratada + outras despesas diretas + depreciação + juros sobre o capital investido)/leite produzido.

O preço do leite foi o de menor coeficiente de variação entre fazendas (Tab. 5), enfatizando que o preço, definido pela indústria, tem caráter mais constante dentro da região que as práticas de produção, definidas pelas fazendas. A correlação entre o preço do leite e o volume de leite produzido foi de 0,53 e, entre a RB total e o volume de leite produzido, foi de 0,99 , indicando que a RB total foi mais determinada pelo volume produzido que pelo preço. A diferenciação de preços pagos pela indústria não foi o fator mais importante na variação da RB total entre fazendas.

A RB leite representou $85 \%$ da RB total, parâmetro com variabilidade baixa entre fazendas (Tab. 5). A fazenda menos dependente de venda de leite para manter o fluxo de renda teve RB leite como proporção da RB total de 57\%. Em Minas Gerais, a participação da renda oriunda do leite na renda bruta total foi $80,3 \%$, chegando a $85 \%$, em alguns extratos de produção (Federação..., 2006). Em Goiás, em uma amostra de 1000 fazendas, a renda do leite representou 83,5\% da renda bruta total (Federação..., 2009), semelhante aos dados deste estudo. Entretanto, Marques et al. (2002) observaram que, em uma amostragem de rebanhos pouco tecnificados de Minas Gerais, a venda de leite contribuiu com $71,9 \%$ da renda bruta total, sugerindo que a participação da venda de animais foi mais representativa em rebanhos com baixo desempenho zootécnico, nos quais a produtividade foi supostamente penalizada. Este fato denota a importância dos fatores ligados à produtividade e à venda do leite e sugere que práticas focadas na venda de animais, mas capazes de comprometer a produção de leite, podem induzir perda significativa na renda das fazendas. 
Tabela 5. Indicadores de renda bruta (RB) e capital investido em bens da amostra de 159 fazendas produtoras de leite da mesorregião Triângulo Mineiro-Alto Paranaíba, MG

\begin{tabular}{lccccc} 
& Média & DP & CV & Min & Max \\
\hline RB leite $(\mathrm{R} \$ /$ ano) & 249781 & 252233 & 101 & 24065 & 2186702 \\
RB total $\left(\mathrm{R} \$\right.$ /ano) $^{1}$ & 287506 & 291984 & 102 & 32617 & 2676587 \\
RB leite/RB total $(\%)^{\text {Preço leite }(\mathrm{R} \$ / \mathrm{L})}$ & 85,5 & 9,3 & 11 & 56,6 & 100,0 \\
Preço leite total (R\$/L) & 0,8523 & 0,0767 & 9 & 0,6342 & 1,0613 \\
Bens (R\$) & 1,0064 & 0,1198 & 12 & 0,7519 & 1,3893 \\
Bens sem terra (R\$) & 801346 & 494601 & 62 & 56579 & 2474558 \\
Terra/Bens $(\%)$ & 327068 & 248770 & 76 & 56579 & 2365167 \\
\hline
\end{tabular}

$\mathrm{DP}=$ desvio-padrão; $\mathrm{CV}=$ coeficiente de variação; Min=valor mínimo; Max=valor máximo. ${ }^{1}$ Considera o valor do leite comercializado adicionado da renda oriunda da venda de animais e produtos excedentes, como esterco e forragens.

O número de funcionários contratados foi linearmente correlacionado ao número de vacas em lactação $(\mathrm{r}=0,83)$ e ao volume diário produzido $(\mathrm{r}=0,87)$. Estes dados indicam que o relacionamento entre a necessidade de trabalho contratado, por vaca ou por litro de leite produzido, foi uma constante. A correlação entre leite produzido por unidade de mão-de-obra contratada e o número de funcionários contratados na fazenda, apesar de positivo, foi de apenas 0,10 . O trabalho da mão-de-obra familiar não reduziu a necessidade de mão-de-obra contratada por vaca ou por volume de produção adicional. Alto uso de mão-de-obra familiar na gerência do negócio, resultando em pouco envolvimento dos membros da família com as práticas de produção inerentes ao negócio leite, pode explicar esses relacionamentos. Apenas $36 \%$ dos fazendeiros moravam na fazenda ou muito próximo dela e estavam presentes diariamente no negócio, apesar de $84 \%$ das propriedades terem o leite como atividade principal da fazenda. Apenas $18,2 \%$ das propriedades tinham a renda da atividade leiteira como $100 \%$ da renda do proprietário.

A produção anual de leite por mão-de-obra contratada foi ao redor de 100000 litros (Tab. 3), acima da observada nas fazendas de Minas Gerais (Federação..., 2006) e Goiás (Federação..., 2009). Entretanto, produções anuais por trabalhador ao redor de 300000 litros foram relatadas no Paraná (Silva et al., 2006), acima do valor máximo observado nesta amostra, ao redor de 220000 litros. O leite produzido por unidade de mão-de-obra contratada (L/ano) foi positivamente correlacionado ao volume diário de produção $(\mathrm{L} / \mathrm{d})$, mas a resposta não foi linear
(Leite/Mão de obra contratada=6055,1 x Leite produzido $\left.^{0,4311} ; r^{2}=0,51 ; P<0,01\right)$. A cada novo incremento na produção diária, o aumento na produção por funcionário contratado foi decrescente, sugerindo que aumento de escala impactou mais o pequeno que o grande produtor.

O custo por litro produzido foi calculado considerando ou não os juros sobre o capital investido na atividade (Tab. 4), sendo de 0,98 a correlação entre CTM1 e CTM2. Pelos dois métodos utilizados, o custo foi menor que a média do preço do leite total recebido pelos produtores da amostra (Tab. 5), refletindo o impacto dos preços favoráveis recebidos pelos produtores de leite na época da coleta dos dados (International..., 2009; Centro..., 2009). Na média, as fazendas conseguiram um resíduo de renda positivo para remunerar os custos, apesar de em $15,1 \%$ e $25,1 \%$ das fazendas, considerando CT1 e CT2, respectivamente, o resíduo ter sido negativo.

A RL média foi positiva, independentemente do método de cálculo do custo (Tab. 6). A TRB calculada pelo CT1 foi de 7,7\% ao ano, maior que o rendimento anual médio da caderneta de poupança no Brasil, ao redor de 6\% (Banco..., 2009). Por este parâmetro, $52 \%$ das fazendas tiveram TRB entre $0 \%$ e $10 \%, 20,1 \%$ das fazendas entre $10 \%$ e $15 \%$ e $13,2 \%$, TRB acima de $15 \%$. O método de cálculo do custo determinou significativamente $\mathrm{o}$ valor dos indicadores de lucratividade. A ML foi praticamente o dobro, quando calculada pelo CT1, comparativamente ao cálculo pelo CT2, e a TRB foi $64 \%$ maior quando calculada pelo CT1, enfatizando o impacto da consideração do custo 
de oportunidade do capital investido na avaliação financeira do negócio. A correlação entre os indicadores de lucratividade (RL, TRB e ML) variou de 0,60 a 0,74 , quando se utilizou a CT1 e de 0,69 a 0,80, para os valores gerados com a CT2, mostrando que, apesar da correlação positiva, o relacionamento entre estas variáveis não é perfeito.

Tabela 6. Indicadores de lucratividade da amostra de 159 fazendas produtoras de leite da mesorregião Triângulo Mineiro-Alto Paranaíba, MG

\begin{tabular}{|c|c|c|c|c|c|}
\hline & Média & DP & CV & Min & Max \\
\hline Renda líquida $1^{1}$ (R $\$$ /ano) & 55350 & 63449 & 115 & -83919 & 378633 \\
\hline Renda líquida $1^{1}$ /bens (\%/ano) & 7,7 & 8,6 & 113 & $-9,9$ & 43,6 \\
\hline Renda líquida $1^{1} /$ Renda bruta $(\%)$ & 17,7 & 18,4 & 104 & $-57,8$ & 57,1 \\
\hline Renda líquida $2^{2}$ (R $\left.\$ / a n o\right)$ & 32841 & 60794 & 185 & -183668 & 333942 \\
\hline Renda líquida $2^{2}$ /bens (\%/ano) & 4,7 & 8,2 & 174 & $-16,8$ & 37,4 \\
\hline 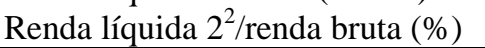 & 8,7 & 21,1 & 242 & $-97,9$ & 50,4 \\
\hline
\end{tabular}

$\mathrm{DP}=$ desvio-padrão; $\mathrm{CV}=$ coeficiente de variação; Min=valor mínimo; Max=valor máximo. ${ }^{1}$ Custo total médio $1=($ despesa com concentrados + despesa com mão-de-obra contratada + outras despesas diretas + depreciação)/leite produzido. ${ }^{2}$ Custo total médio $2=($ despesa com concentrados + despesa com mão-de-obra contratada + outras despesas diretas + depreciação + juros sobre o capital investido)/leite produzido.

Tabela 7. Indicadores de renda líquida (RL) da amostra de 159 fazendas produtoras de leite da mesorregião Triângulo Mineiro-Alto Paranaíba, MG

\begin{tabular}{|c|c|c|c|c|c|}
\hline & Média & DP & $\mathrm{CV}$ & Min & Max \\
\hline $\mathrm{RL}^{1}$ /vaca em lactação (R\$/ano) & 872 & 849 & 97 & -2211 & 3029 \\
\hline $\mathrm{RL} 1$ 1/vaca adulta (R $\$ /$ ano) & 665 & 669 & 101 & -1469 & 2642 \\
\hline RL1 1/mão-de-obra (R\$ano) & 21138 & 20918 & 99 & -42016 & 74016 \\
\hline RL1 1/área (R\$/ha/ano) & 622 & 828 & 133 & -1356 & 4366 \\
\hline $\mathrm{RL} 2^{2} /$ vaca em lactação (R $\$$ /ano) & 499 & 901 & 181 & -3742 & 2672 \\
\hline $\mathrm{RL}^{2} /$ vaca adulta (R $\$ /$ ano $)$ & 393 & 686 & 174 & -2486 & 2330 \\
\hline RL2 ${ }^{2} /$ mão-de-obra (R $\$$ /ano) & 12690 & 21125 & 166 & -71117 & 66452 \\
\hline $\mathrm{RL}^{2}$ /área (R $\$ /$ ha/ano) & 372 & 786 & 211 & -1996 & 3592 \\
\hline
\end{tabular}

$\mathrm{DP}=$ desvio-padrão; $\mathrm{CV}=$ coeficiente de variação; Min=valor mínimo. Max=valor máximo. ${ }^{1}$ Renda Líquida1: Custo total médio $1=($ despesa com concentrados + despesa com mão-de-obra contratada + outras despesas diretas + depreciação)/leite produzido. ${ }^{2}$ Renda Líquida2: Custo total médio $2=($ despesa com concentrados + despesa com mãode-obra contratada + outras despesas diretas + depreciação + juros sobre o capital investido)/leite produzido.

A RL por vaca, mão-de-obra ou área foi determinada pela metodologia de cálculo do custo (Tab. 7). Considerando que a RL1 foi calculada a partir do CT que não imputou juros sobre o capital e sem remuneração da mão-deobra familiar, o valor encontrado precisa ser tratado como um resíduo (Matsunaga et al., 1976) destinado a remunerar estes dois fatores $\mathrm{e}$ também o empresário. A RL2, pela teoria do custo (Schuh, 1976), é também um resíduo, mas, neste caso, destinado a remunerar somente a mão-de-obra familiar e o empresário. Os dois indicadores são importantes para decisões de curto prazo, mas não são perfeitos para estabelecer comparações com outras opções de investimentos.

\section{CONCLUSÕES}

Apesar de as fazendas estudadas terem indicadores de desempenho acima da média das fazendas brasileiras e mineiras, eles são modestos quando comparados a indicadores internacionais ou aos de fazendas tecnificadas de outras regiões do Brasil, sugerindo que existe oportunidade para ganho em eficiências produtiva e provavelmente financeira. 


\section{REFERÊNCIAS}

BANCO CENTRAL DO BRASIL, Brasília, 2009. Disponível em: <http://www4.bcb.gov.br/ pec/taxas/port/ptaxnpesq.asp?id=txcotacao\&id=t xcotacao> Acessado em: 15 out. 2009.

BOLTON, K.; VANDERLIN, J. Milk production costs in 2007 on selected Wisconsin dairy farms. 2009. Cente'r for dairy Profitability; University of Wisconsin-Madison/Extension. Disponível em:

http://cdp.wisc.edu/pdf/08\%20Know\%20Your\% 20COP.pdf>. Acessado em: 03 jul. 2009.

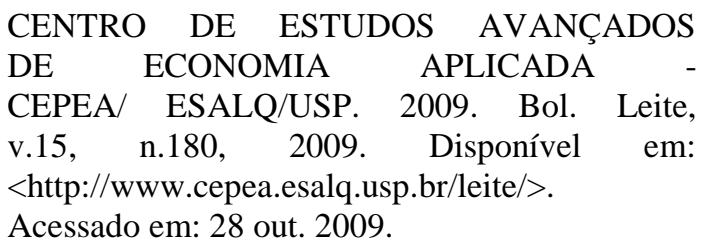

FEDERAÇÃO DE AGRICULTURA DO ESTADO DE GOIÁS. Diagnóstico da cadeia produtiva do leite de Goiás. Goiânia: FAEG, 2009. 64p.

FEDERAÇÃO DE AGRICULTURA DO ESTADO DE MINAS GERAIS. Diagnóstico da pecuária leiteira do estado de Minas Gerais em 2005: relatório de pesquisa. Belo Horizonte: FAEMG, 2006. 156p.

FASSIO, L.H.; REIS, R.P.; GERALDO, L.G. Desempenho técnico e econômico da atividade leiteira em Minas Gerais. Ciênc. Agrotec., v.30, p.1154-1161, 2006.

FOOD AND AGRICULTURAL ORGANIZATION OF THE UNITED NATIONS - Faostat. 2009 Disponível em: <http:faostat.Fao.org/site/569/ DesktopDefault.aspx?PageIK=569\#ancor $>$ Acessado em: 27 out. 2009.

FUNDAÇÃO GETÚLIO VARGAS/Instituto Brasileiro de Economia, Rio de Janeiro, 2009. Disponível em: <http://www.fgvdados.com.br/ dsp_frs_pai_ferramentas.asp > Acessado em: 15 out. 2009.

INSTITUTO BRASILEIRO DE GEOGRAFIA E ESTATÍSTICA. Pesquisa Pecuária Municipal. Sidra/IBGE, Rio de Janeiro, 2009. Disponível em:

$<$ http://sidra.ibge.gov.br/bda/acervo/acervo2.asp? $\mathrm{ti}=1 \& \mathrm{tf}=99999 \& \mathrm{e}=\mathrm{c} \& \mathrm{p}=\mathrm{PP} \& \mathrm{v}=106 \& \mathrm{z}=\mathrm{t} \& \mathrm{o}=23$

>. Acessado em: 05 mar. 2010.
INSTITUTO BRASILEIRO DE GEOGRAFIA E ESTATÍSTICA. Pesquisa Pecuária Municipal. Sidra/IBGE, Rio de Janeiro, 2011. Disponível em: <http://www.ibge.gov.br/cidadesat/link.php? codmun=313740>. Acessado em: 30 nov. 2011

INTERNATIONAL FARM COMPARISON NETWORK. Dairy Report 2009: for a better understanding of milk production world-wide. Kiel:IFCN Dairy Research Center, 2009. 206p.

LATRUFFE, L.; BALCOMBE, K.; DAVIDOVA, S. et al. Determinants of technical efficiency of crop and livestock farms in Poland. University of Paris, France, 2004. Disponível em: <http://ideas.repec.org/a/taf/applec/ v36y2004i12p1255-1263.html> Acessado em: 02 dez. 2009.

MARQUES, V. M.; REIS, R.P.; SÁFADI, T. et al. Custos e escala na pecuária leiteira: estudo de casos em Minas Gerais. Ciênc. Agrotec., v. 26, p. 1027-1034, 2002.

MATSUNAGA, M.; BEMELMANS, P.F.; TOLEDO, P.E.N. et al. Metodologia de custo de produção utilizada pelo IEA. Agric. São Paulo, v.23, p.123-139, 1976.

MINAS GERAIS. Secretaria de Estado da Agricultura, Pecuária e Abastecimento do Estado de Minas Gerais. Dados do agronegócio mineiro e brasileiro. Disponível em:

<http://www.agricultura.mg.gov.br/dados_1.asp> . Acesso em: 18 fev. 2010.

NASCIF, C. Indicadores técnicos e econômicos em sistemas de produção de leite de quatro mesorregiões do Estado de Minas Gerais. 2008. 98 p. Dissertação (Mestrado em Zootécnica) Universidade Federal de Viçosa, Viçosa, MG, 2008.

NEW ZEALAND DAIRY. National dairy statistics 2007-2008. Disponível em: <http://www.dairynz.co.nz/file/fileid/11947> Acesso em: 16 jan. 2010.

OLIVEIRA, T.B.A.; FIGUEREDO, R.S.; OLIVEIRA, M.W. et al. Índices técnicos e rentabilidade da pecuária leiteira. Sci. Agric., v.58, p.687-692, 2001.

REIS, R.P.; MEDEIROS, A.L.; MONTEIRO, L.A. Custos de produção da atividade leiteira na Região Sul de Minas Gerais. Org. Rurais Agroind., v.3, p.45-54, 2001. 
SCHIFFLER, E.A.; MÂNCIO, A.B.; GOMES, S.T. et al. Efeito da escala de produção nos resultados econômicos da produção de leite B no Estado de São Paulo. Rev. Bras. Zootec., v.28, p.425-431, 1999.

SERVIÇO BRASILEIRO DE APOIO ÀS MICRO E PEQUENAS EMPRESAS SEBRAE. Projeto Educampo. Homepage do projeto. Belo Horizonte, 2008. Disponível em:<http://www.cpdeducampo.com.br/novosite/ EducampoHistorico.htm>. Acessado em: 9 set. 2009.

SCHUH, G. E. Considerações teóricas sobre custos de produção na agricultura. Agric. São Paulo, v.23, p.97-121, 1976.

SILVA, H.A. da; JANSSEN, H.P.; APPELT, J.V. et al. Resultados econômicos de sistemas de produção de leite com diferentes níveis tecnológicos na Cooperativa Agropecuária Castrolanda. In: CONGRESSO PANAMERICANO DO LEITE, 9., 2006, Porto Alegre. Anais... Porto Alegre, 2006.
STOCK, L. A. Sistemas-referência para estudo sobre fazendas típicas de produção de leite do Brasil. Bol. CBLeite, Juiz de Fora, v.1, p.12-17, 2007.

UNITED STATES DEPARTMENT OF AGRICULTURE. 2012. USDA. Dairy: World Markets and Trade. Disponível em: $<$ http://usda01.library.cornell.edu/usda/current/d airy-market/dairy-market-07-12-2012.pdf> Acessado em: $5 \mathrm{dez} 2012$.

VILELA, D.; LIMA, J.A. de; RESENDE, J.C. et al. Desempenho de vacas da raça holandesa em pastagem de coast-cross. Rev. Bras. Zootec., v.35, p.555-561, 2006. 